\title{
Hyperbaric Oxygen Induces Basic Fibroblast Growth Factor and Hepatocyte Growth Factor Expression, and Enhances Blood Perfusion and Muscle Regeneration in Mouse Ischemic Hind Limbs
}

\author{
Tetsuichi Asano, MD; Eiji Kaneko, MD; Shohei Shinozaki, MS; Yutaka Imai, MD; \\ Masaharu Shibayama, $\mathrm{PhD}^{*}$; Tsuyoshi Chiba, PhD; Masumi Ai, MD; \\ Akio Kawakami, MD; Hiroshi Asaoka, MD; Toru Nakayama, MD*; \\ Yoshihiro Mano, MD*; Kentaro Shimokado, MD
}

\begin{abstract}
Background It is not clear how hyperbaric oxygen therapy (HBO) affects ischemia-induced pathophysiological responses such as angiogenesis and skeletal muscle regeneration. In the present study the effects of $\mathrm{HBO}$ on the functional and morphological recovery of ischemic hind limbs, blood perfusion and the local production of angiogenic growth factors were studied in a mouse model.

Methods and Results Mice were placed in pure oxygen under $3 \mathrm{~atm}$ for $1 \mathrm{~h} /$ day for 14 days after the removal of a segment of the left femoral artery. HBO-treated mice showed better functional recovery and greater blood flow in the ischemic hind limb than untreated mice. Histological examination revealed unatrophied muscle fibers with islands of small regenerating muscle cells only in HBO-treated mice. Regeneration of muscle was confirmed by the increase in myf5 mRNA. The amount of mRNA for vascular endothelial growth factor (VEGF), hepatocyte growth factor (HGF) and basic fibroblast growth factor (bFGF) was slightly increased in the ischemic hind limbs. HBO eliminated the increase in VEGF mRNA. In contrast, the amount of mRNA for bFGF and HGF was further increased by $\mathrm{HBO}$ treatment. $\mathrm{HBO}$ transiently increased early growth response protein 1 (Egr-1) in the ischemic hind limbs.

Conclusions HBO accelerates the recovery of ischemic hind limbs by increasing the production of bFGF and HGF and by promoting muscle regeneration in mice. (Circ J 2007; 71: 405-411)
\end{abstract}

Key Words: Angiogenic growth factors; Angiogenesis; Hyperbaric oxygen; Ischemic limb; Skeletal muscle

$\mathbf{H}$ yperbaric oxygen therapy (HBO) has been used to treat chronic ulcers of the lower limbs such as in diabetic foot and peripheral artery occlusive diseases! However, the effect of HBO on pathophysiological tissue responses to hypoxia, particularly the effect on ischemia-induced production of angiogenesis, remains mostly unknown. Ischemia induces angiogenesis by increasing the production of angiogenic growth factors? such as vascular endothelial growth factor (VEGF), which is upregulated in ischemic tissues?,4 HIF-la, a transcription factor, plays a critical role in the upregulation of VEGF. Hypoxia inhibits the breakdown of HIF-la and causes its accumulation without increasing its transcription. HIF-la binds to the hypoxia-responsive element in the promoter region of VEGF and increases its transcription? HBO may inhibit the accumulation of HIF-la by relieving tissue hypoxia and potentially decreasing the compensatory induction of genes, including VEGF. Basic fibroblast growth factor (bFGF) is also upregulated in ischemic tissues, and

(Received August 29, 2006; revised manuscript received December 7 , 2006; accepted December 13, 2006)

Geriatrics and Vascular Medicine, *Occupational Health Education, Tokyo Medical and Dental University Graduate School, Tokyo, Japan Mailing address: Kentaro Shimokado, MD, Geriatrics and Vascular Medicine, Tokyo Medical and Dental University Graduate School, 1-545 Yushima, Bunkyo-ku, Tokyo 113-8519, Japan. E-mail: k.shimoka. vasc@tmd.ac.jp early growth response protein 1 (Egr-1) regulates transcription of bFGF, which, in turn, induces expression of Egr-16,7 In contrast to VEGF and bFGF, hepatocyte growth factor (HGF) is reportedly downregulated by ischemia in some animals? Thus, HBO may favor angiogenesis driven by HGF.

Hypoxia influences the proliferation, growth and functions of skeletal muscle, and may affect recovery from ischemic injury through its effect on skeletal muscle?-12 Acute ischemia induces gradual deterioration of energy metabolism in muscle, followed by cell death or adaptation. Proliferation of satellite cells begins as early as 3 days after the ischemic insult ${ }^{10}$ Ischemia inhibits both proliferation and differentiation of myoblasts partly by accelerating Myo D degradation. ${ }^{11}$ More importantly, muscle is a major source of angiogenic growth factors. Ischemia caused by physical exercise or arterial occlusion induces VEGF expression in the ischemic skeletal muscle, and accelerates angiogenesis! ${ }^{3}$ VEGF, HGF and bFGF all have myotropic effects, ${ }^{14,15}$ forming a positive feedback loop for angiogenic growth factor production and the proliferation and growth of skeletal muscle.

Based on these findings, HBO could potential exert 2 opposing effects on the outcome of ischemia. It may lead to improvement by increasing HGF production and preventing skeletal muscle injury or it may suppress the process of physiological adaptation to ischemia, such as upregulation 

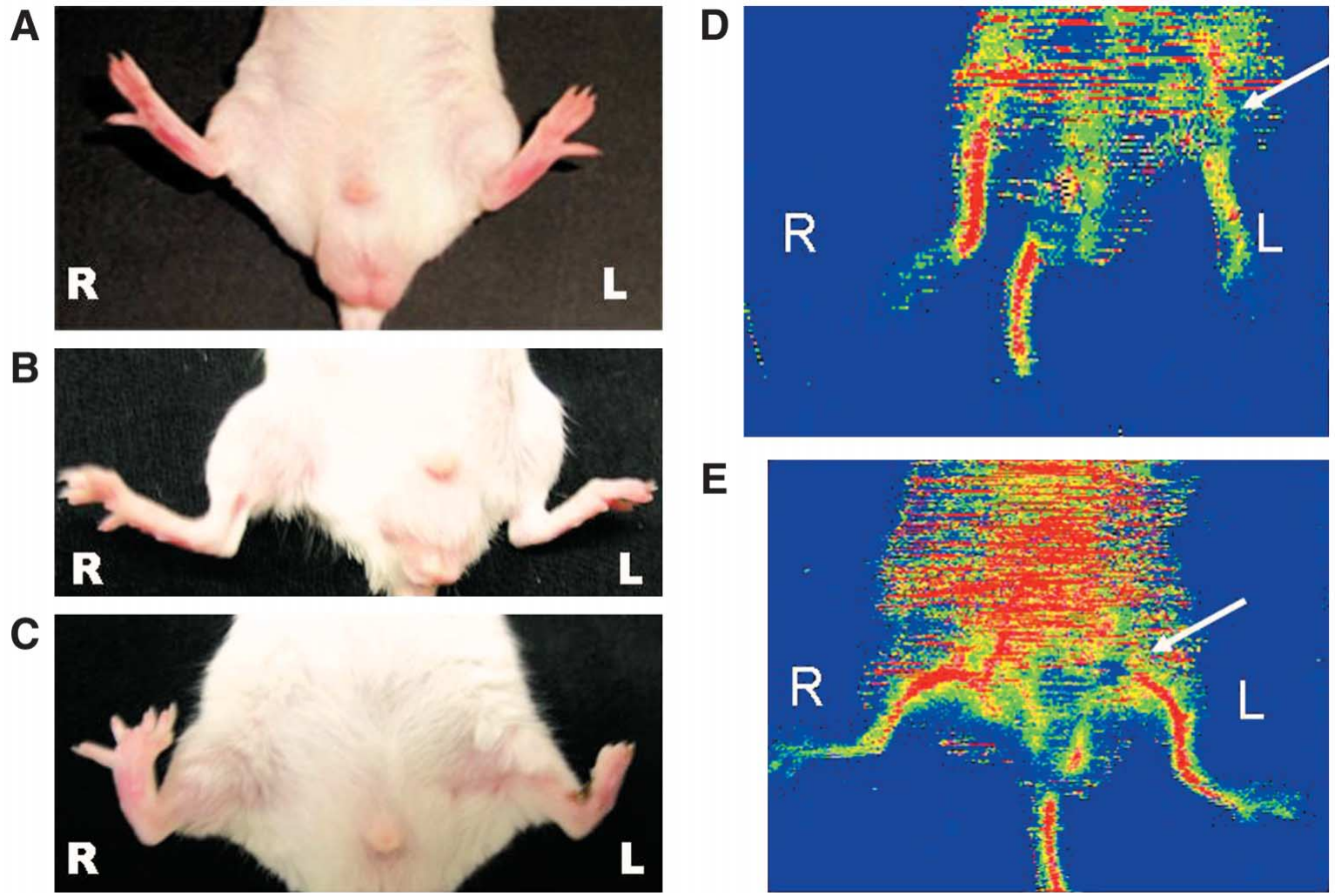

E

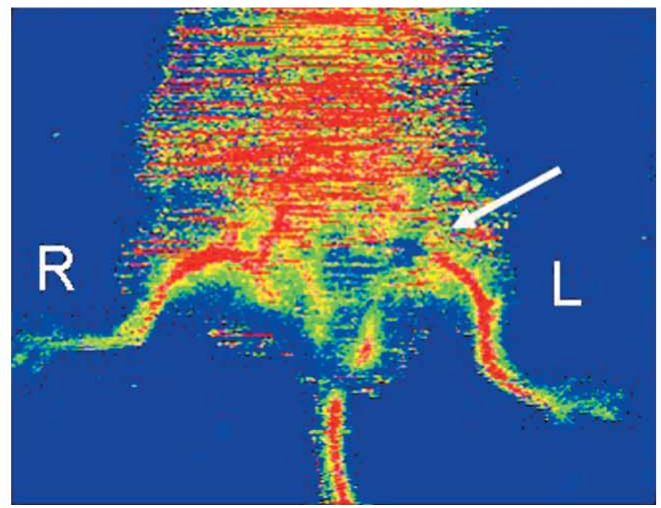

Fig 1. Hyperbaric oxygen therapy (HBO) effects on muscles (A-C) and blood flow (D-E). Hindlimbs were photographed without anesthesia 2 weeks after the induction of ischemia in the left hind limb (L). (A) Mouse without ischemia, (B) untreated mouse with ischemia, (C) mouse with ischemia treated with HBO. Note that only the untreated mouse (B) shows drop foot. Blood flow of the ischemic hind limb was determined with a laser Doppler imaging 2 weeks after the induction of ischemia. (D) Mice with ischemia that was not treated with HBO, (E) mice with ischemia that was treated with HBO. Arrow indicates the point where the femoral artery was ligated and excised.

of VEGF, and delay the recovery. In this study, we investigated the effect of HBO on the production of angiogenic growth factors, the adaptation of ischemic skeletal muscle and its subsequent functional recovery in a mouse model.

\section{Methods}

Animals and Experimental Design

Male BALB/c mice (7 weeks old) were purchased from Clea Japan Co Ltd (Tokyo, Japan). All animal experiments were done under approved protocols and in accordance with recommendations for the proper care and use of laboratory animals by the Committee for Animal Welfare at Tokyo Medical and Dental University. Mice were anesthetized with an intraperitoneal injection of sodium pentobarbital, the proximal left femoral artery was ligated at 2 points $3 \mathrm{~mm}$ apart, and the artery between the ligatures was excised. A group of mice were placed in $100 \%$ oxygen under $3 \mathrm{~atm}$ for $1 \mathrm{~h} /$ day for 14 days in a hyperbaric chamber. At various time points, mice were killed and both gastrocnemius muscles were excised. At days 1, 7 and 14, mice were assessed for functional recovery by 2 independent observers ${ }^{16}$

\section{Laser Doppler Perfusion Imaging}

Blood flow was measured with a laser Doppler perfusion image analyzer (Moor Instruments Co Ltd, Devon, UK)?

\section{Histological Examination}

Paraffin-embedded sections of gastrocnemius muscle were stained with hematoxylin-eosin. The density and short length of muscle fibers were determined by NIH image in a blinded manner. Vasculature in the ischemic gastrocnemius muscle was determined by immunohistological staining using anti mouse PECAM-1 monoclonal antibody (BD Japan, Tokyo Japan). Three sections from each mice were examined with purified anti-mouse CD31 (PECAM-1) and biotinylated anti-rat IgG (BA-4000, Vector Laboratories, Burlingame, CA)! ${ }^{17}$

\section{Real-Time Polymerase Chain Reaction (PCR)}

Real-time PCR was performed with a LightCycler (Roche Molecular Biochemicals Basel, Switzerland) according to the manufacturer's instructions. The amount of mRNA for the target molecules was standardized to GAPDH or $\beta$ actin. Primers used were as follows:

bFGF: (F) 5'-AGCGACCCACACGTCAAACTAC-3'

(R) 5'-CAGCCGTCCATCTTCCTTCATA-3'

FGFR: (F) 5'-GCGATGTGTGGTCTTTTGGAGT-3'

(R) 5'-TCCATTCGATGACCCTCCTTC-3'

HGF: (F) 5'-TGCCCTATTTCCCGTTGTGA-3'

(R) 5'-CCATTTACAACCCGCAGTTGTT-3'

VEGF: (F) 5'-TGCACCCACGACAGAAGG-3'

(R) 5'-GCACACAGGACGGCTTGA-3'

myf5: (F) 5'-GTCAACCAAGCTTTCGAGACG-3'

(R) 5'-CGGAGCTTTTATCTGCAGCAC-3'

Egr-1: (F) 5'-CTTTCGGTTTGGGGCTGGACA-3'

(R) 5'-CGCTGCTGGTGCTGCTGCTGCTAT-3' 


\section{Statistical Analysis}

The data are presented as the mean \pm SEM. Differences were analyzed by ANOVA, Student's t-test, and Wilcoxon matched-pairs signed-ranks test when there was a significant difference. $\mathrm{P}<0.05$ was considered statistically significant.

\section{Results}

\section{Recovery of the Ischemic Hind Limb}

We evaluated the recovery of ischemic hind limbs by 4 methods: gross appearance, blood flow, movement and histology. In untreated mice, the ischemic hind limbs were atrophic and contracted (Fig 1B), whereas they were less atrophic and not contracted in mice treated with $\mathrm{HBO}$ (Fig 1C). Blood flow was improved in the treated mice but not in the untreated mice (Figs 1D,E). Blood flow through the segment of excised artery was completely restored by collaterals in all mice treated with HBO (Fig 1E). Functional recovery was assessed by scoring the movement of the ischemic limbs (Fig 2), which was severely impaired in the untreated mice compared with the treated mice.

Histological examination revealed almost normal muscle fibers in the HBO-treated mice (Figs 3A,C). In untreated mice, muscles were atrophic, and the number of nuclei of both muscles and pericytes was decreased. The extracellular space had widened, and capillaries were barely observed. Adipose tissue was not observed in untreated ischemic hind limbs. No apparent necrosis was observed in this model (Fig 3B). All changes were quantitatively analyzed. The density of both muscle fibers and nuclei decreased in the ischemic hind limbs, and HBO significantly reduced that decrease (Figs 4A,B).

There were islands of small eosinophilic muscle cells with

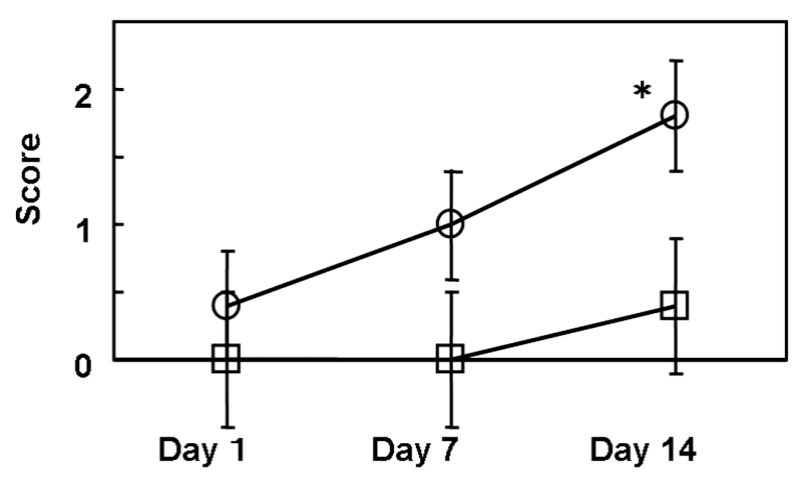

Fig 2. Functional recovery of ischemic hind limbs. At days 1, 7, and 14 , mice were assessed for the functional recovery by 2 independent observers, and quantitatively analyzed: $0=$ lack of any visible mobility, and $3=$ mobility equal to nonischemic hind limbs, with scores 1 and 2 in between. Statistical analysis was performed by Wilcoxon matchedpairs signed-ranks test. $(\bigcirc)$ Mice treated with hyperbaric oxygen therapy (HBO), ( $\square$ ) mice not treated with $\mathrm{HBO}$ after the induction of ischemia. Each point represents the mean \pm SEM of 5 mice. ${ }^{*} \mathrm{p}<0.05$ vs mice without $\mathrm{HBO}$.

an increased number of nuclei (Fig 3D) in the treated animals only. The number of PECAM-1-positive cells increased in the HBO-treated mice compared with the untreated mice, indicating an increase in capillaries in the treated mice (Figs 3E, F, 4C).

\section{Regeneration of Muscle in Ischemic Hind Limbs}

Because the histological examination showed islands of small eosinophilic cells, which met the criteria of regenerating skeletal muscle, 210 in the HBO-treated mice (Fig 3D),

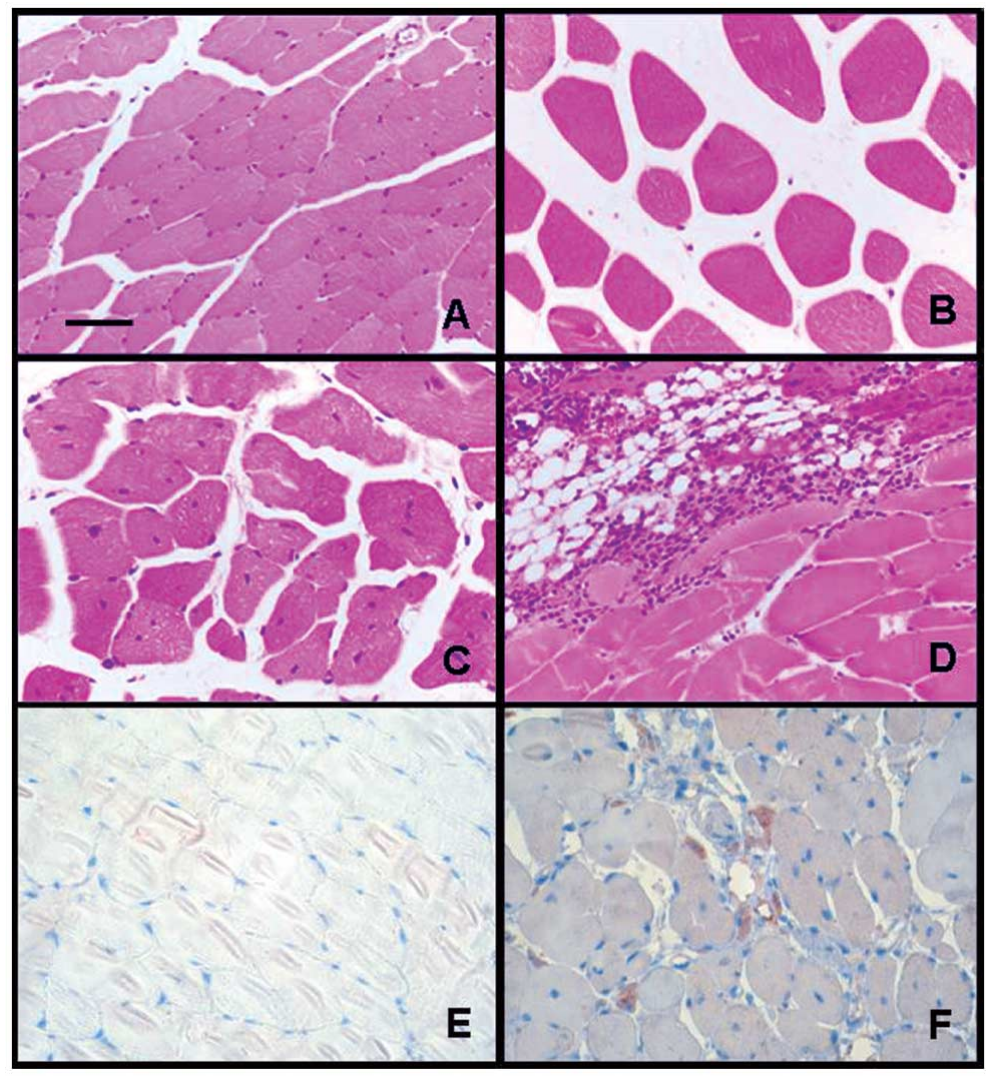

Fig 3. Histopathological analysis. Paraffin-embedded sections of gastrocnemius muscle stained with hematoxylin-eosin (A-D) and anti-PECAM-1 antibody (E,F). (A) Nonischemic muscle, (B) ischemic muscle untreated with hyperbaric oxygen therapy (HBO), (C) ischemic muscle treated with $\mathrm{HBO}$, (D) same as $\mathrm{C}$ showing regenerating muscle cells that are small in size and more eosinophillic. Serial sections were stained with antiPECAM-1 antibody (E,F). (E) Ischemic muscle without HBO, (F) ischemic muscle with HBO. Same experiment was repeated twice with the same results. Bar $=100 \mu \mathrm{m}$. 
A

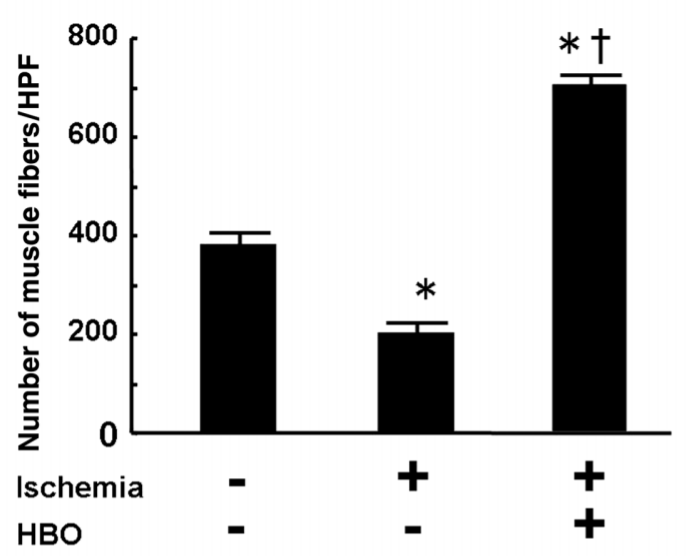

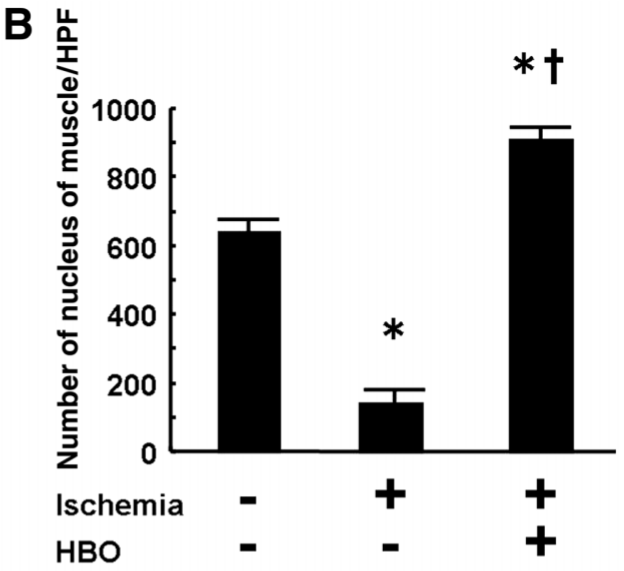

C

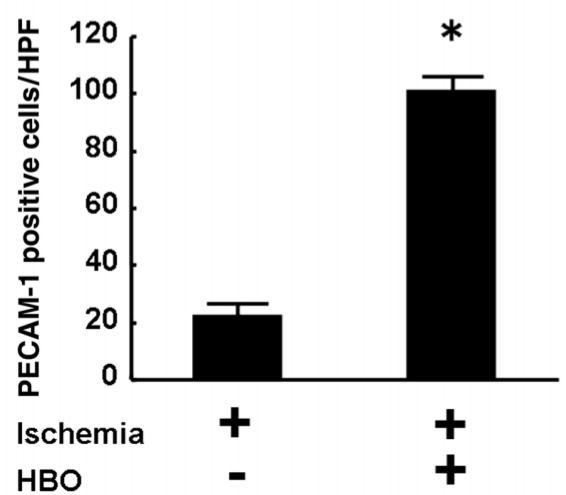

Fig 4. Quantitative analysis of regeneration of muscle and increased vasculature in ischemic hind limbs after hyperbaric oxygen therapy (HBO). The histopathological findings presented in Fig 3 were quantitatively analyzed. The density of muscle fibers (A), and numbers of nuclei of muscle (B) and PECAM-1-positive capillary endothelial cells (C) were determined in 10 high-power fields (HPF) of 9 sections prepared from 3 mice for each group. Bars $=$ mean \pm SEM. *p $<0.01$ vs control, $\dagger \mathrm{p}<0.01$ vs without HBO.

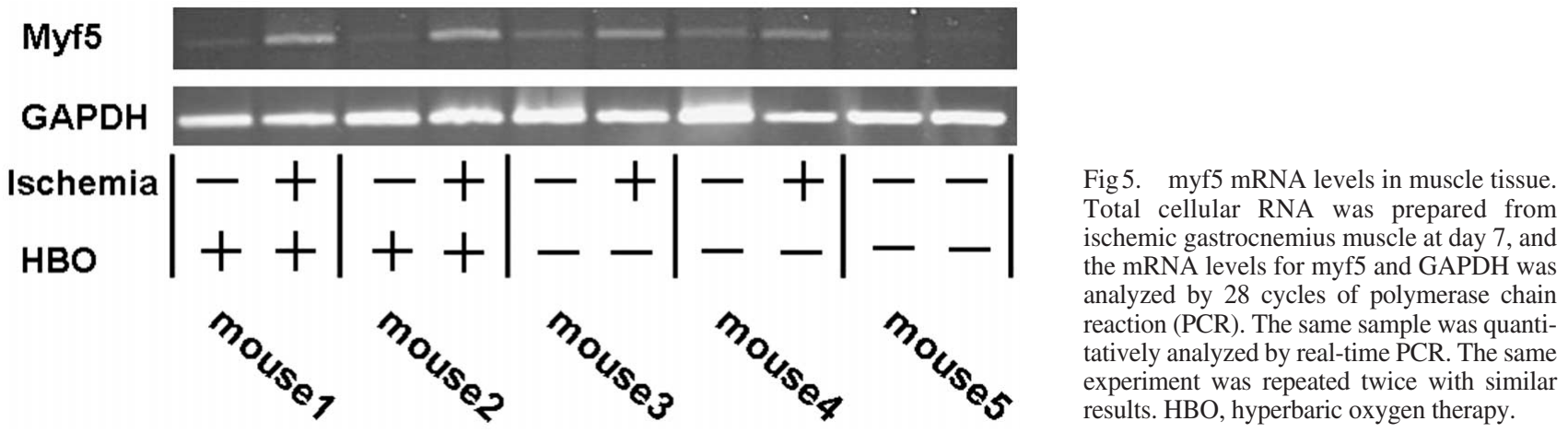

we then determined the amount of myf5 mRNA that was specifically expressed in the developing muscles. Messenger RNA for myf5 was significantly increased in the ischemic hind limbs of mice treated with HBO than in the untreated mice. Myf5 mRNA was not induced in sham-operated mice (Fig 5, mouse 5), confirming that HBO treatment accelerated muscle regeneration in the ischemic limb.

\section{Induction of VEGF Expression}

The amount of VEGF mRNA, which is known to be induced by ischemia, was increased in ischemic hind limbs at $24 \mathrm{~h}$ after the induction of ischemia, further increased at
$72 \mathrm{~h}$, and returned to baseline by day 14 . HBO treatment completely abolished the increase in VEGF mRNA in ischemic hind limbs (Fig 6A).

\section{Induction of bFGF and $H G F$}

The amount of bFGF and HGF mRNA showed a similar time-dependent increase after ischemia with a peak value at 24 or $72 \mathrm{~h}$. In contrast to VEGF mRNA, bFGF and HGF mRNA further increased when mice were treated with HBO. Ischemia itself significantly increased the amount of mRNA for both factors (Figs 6B,C). Similarly, bFGF receptor mRNA was significantly increased by HBO in ischemic 
A

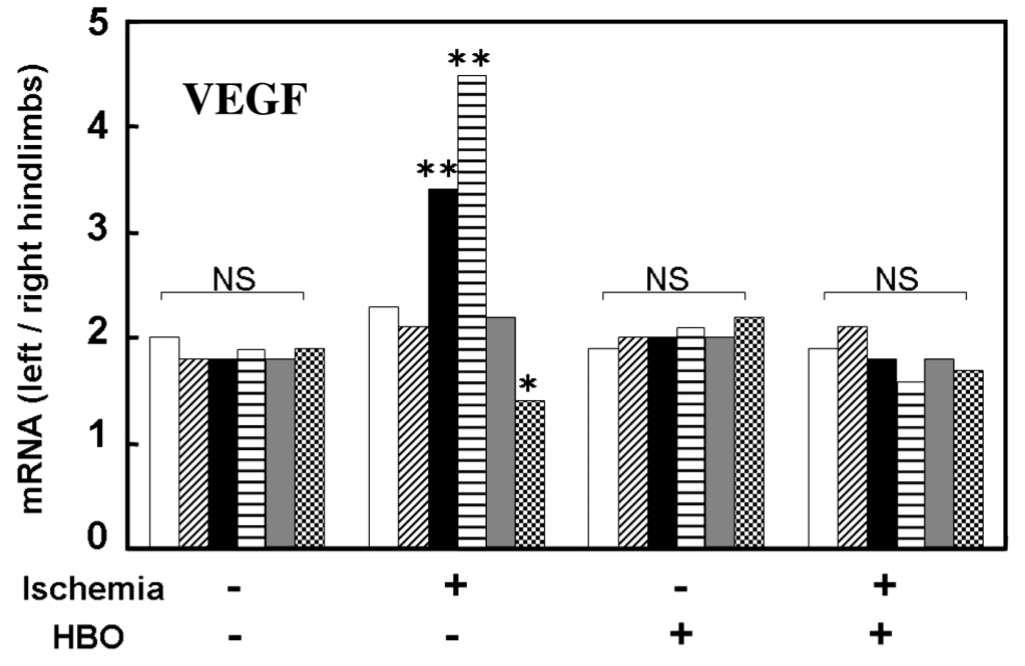

B

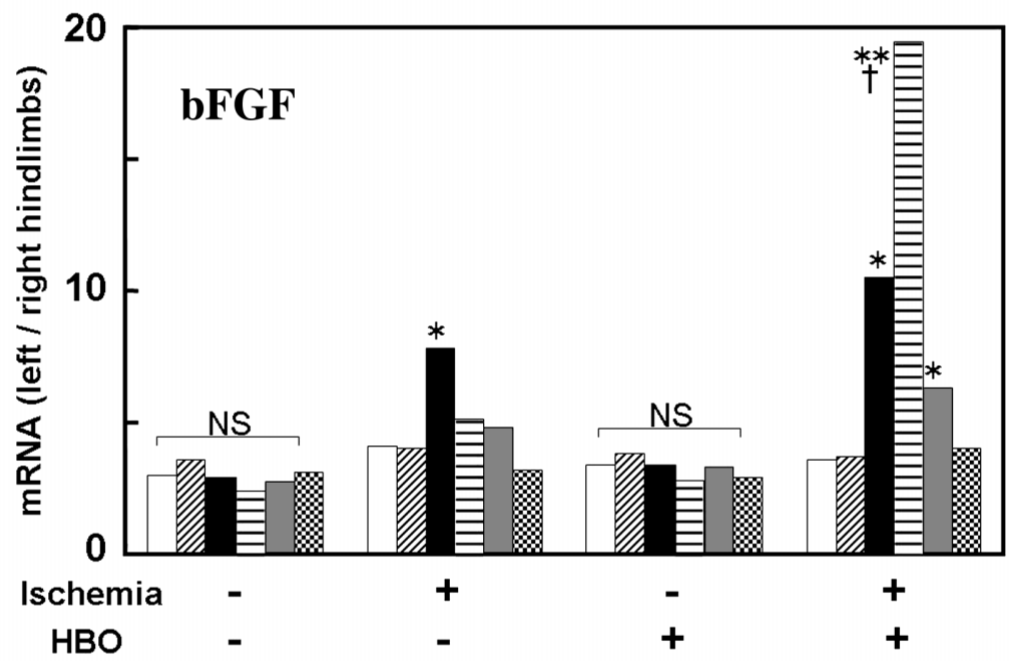

C

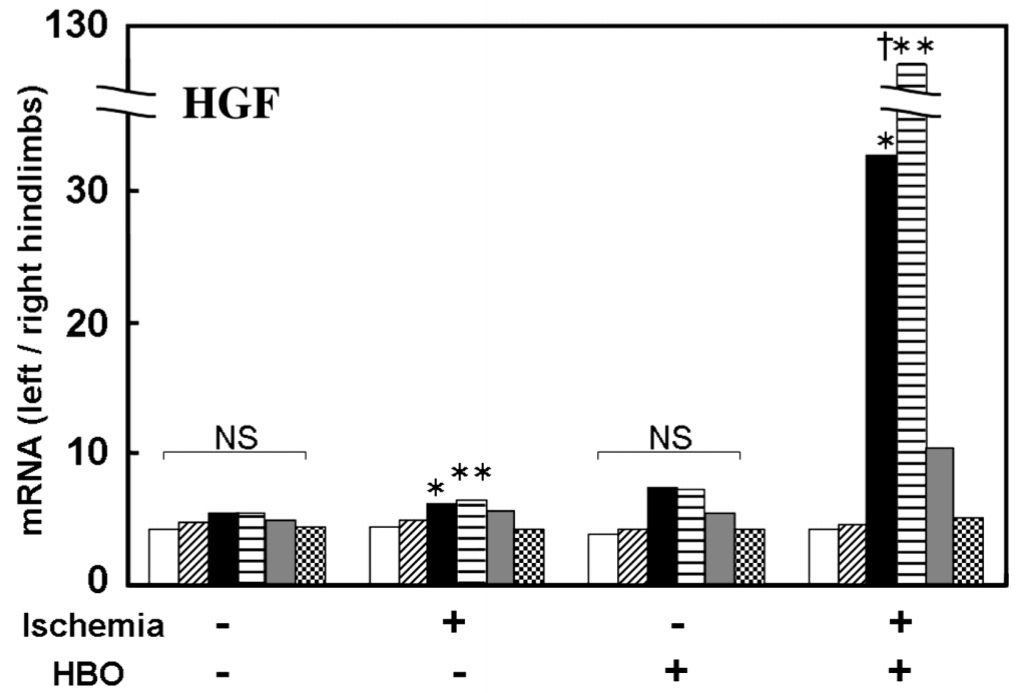

Fig 6. Levels of mRNA of angiogenic growth factors in ischemic hind limbs. Total cellular RNA was prepared from gastrocnemius muscle at indicated time points after the induction of ischemia. The amounts of mRNA for vascular endothelial growth factor (VEGF) (A), basic fibroblast growth factor (bFGF) (B) and hepatocyte growth factor (HGF) (C) were determined by real-time polymerase chain reaction (PCR), and expressed as the ratio of that of the ischemic limb to that of the nonischemic limb. Open column: $3 \mathrm{~h}$, shaded column: $12 \mathrm{~h}$, closed column: $24 \mathrm{~h}$, hatched column: $72 \mathrm{~h}$, gray column: 7 days, and dotted column: 14 days. Each column represents the mean of 5 animals. ${ }^{*} \mathrm{p}<0.05$, $* * \mathrm{p}<0.01$ vs $3 \mathrm{~h},{ }^{\dagger} \mathrm{p}<0.01$ vs $72 \mathrm{~h}$ ischemia without hyperbaric oxygen therapy (HBO). hind limbs (data not shown). HBO itself did not affect the amounts of mRNA for these growth factors when ischemia was not induced (Figs 6A-C).

To get an insight into the mechanism, we studied whether Egr-1, a transcription factor that increases bFGF mRNA, 6,7 was increased by HBO. Ischemia increased the amount of
Egr-1 mRNA in the ischemic hind limb but it was not detected in nonischemic limbs. There was no difference between the 2 groups at $3 \mathrm{~h}$. In HBO-treated mice, the amount of Egr-1 mRNA further increased at $6 \mathrm{~h}$ and decreased at $12 \mathrm{~h}$, whereas it sharply decreased at $6 \mathrm{~h}$ in untreated mice (Fig 7). 


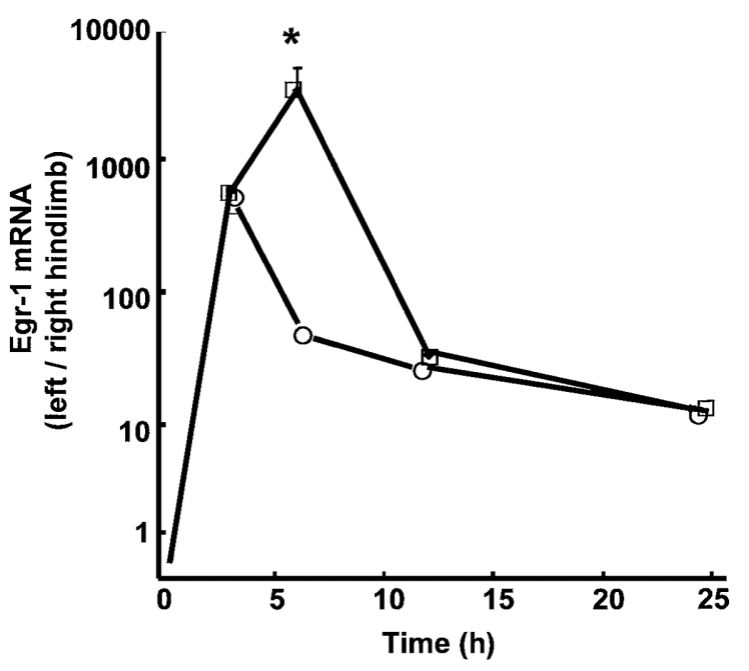

Fig 7. Levels of early growth response protein 1 (Egr-1) mRNA. Total cellular RNA was prepared from ischemic gastrocnemius muscle at various time points after the induction of ischemia, and the amount of Egr-1 mRNA was determined by real-time polymerase chain reaction. ( $\square$ ) Mice given hyperbaric oxygen therapy for $1 \mathrm{~h}$ after the induction of ischemia, $(\bigcirc)$ mice kept under normal oxygen pressure. Each point represents the mean \pm SEM of 6 mice. ${ }^{*} p<0.01$.

\section{Discussion}

In this study, we have shown that HBO improves blood flow and functional recovery of ischemic hind limbs. The accelerated recovery was attributed to increased production of angiogenic growth factors, increased vasculature development and enhanced regeneration of ischemic skeletal muscle. HBO enhanced the expression of bFGF and HGF, whereas it suppressed hypoxia-dependent VEGF expression. Accelerated muscle regeneration was evidenced by characteristic morphology and increase in mRNA for myogenic regulatory factors such as myf5.

An important finding is that HBO enhanced ischemia-induced induction of bFGF and HGF. Previous reports have revealed that the production of bFGF and HGF increased in the ischemic hind limbs of mice, ${ }^{18}$ but the extent of the change was rather small compared with the massive increase achieved by therapeutic gene transfection of these factors, 4.8 In our study, the mRNA levels for both bFGF and HGF were slightly but significantly increased in the ischemic hind limbs, and dramatically increased by HBO to the same extent as achieved by gene therapy. HBO itself did not increase the mRNA for these factors in the absence of ischemia, indicating that $\mathrm{HBO}$ exaggerated the ischemiainduced events.

HBO inhibited the ischemia-induced expression of VEGF, which confirms previous reports that hypoxia directly induces VEGF production through accumulation of HIF-la 5 VEGF, and bFGF (and HGF also in our study) are upregulated by ischemia, and gene therapy using any of them promotes recovery of blood perfusion, $, 8,19$ However, bFGF deficiency does not affect the recovery of ischemic hind limbs ${ }^{20}$ Our findings also show that suppression of VEGF production does not affect the recovery of ischemic muscle if there are other factors such as HGF and bFGF present. These findings indicate that redundant angiogenic growth factors are produced in ischemic limbs and likely play an overlapping role in angiogenesis of mice.

Egr-1 mRNA was transiently increased in the ischemic limbs, and HBO accentuated and prolonged this increase. Egr-1 upregulates the expression of bFGF in various cell types, including vascular cells.6,7 Egr-1 DNAzyme inhibits Egr-1 protein expression and FGF-dependent angiogenesis both in vitro and in vivo. ${ }^{21}$ Concomitantly, adenovirusmediated delivery of Egr-1 accelerates revascularization in mouse hind limb ischemia? The findings of those previous studies indicate that the transient increase in Egr-1 that we observed may account for the enhanced expression of bFGF. Mechanisms of upregulation of Egr-1 are unclear, but one possibility is that ischemic injury causes local release of bFGF or HGF that is stored in the cell or extracellular matrix, and then these growth factors activate Egr-1?2

Another important finding is that $\mathrm{HBO}$ enhanced the regeneration of ischemic muscle. In our model, the ischemic injury was almost completely recovered by $\mathrm{HBO}$, but incompletely recovered if HBO was not given. Functional recovery was accompanied by muscle regeneration that was confirmed by histological examination and the expression of myogenic regulatory factors such as myf5. Muscle regeneration, as well as decreased apoptosis of the muscle cells, may play an important role in functional recovery of ischemic tissues? ${ }^{23}$

Muscle regeneration, collateral formation and angiogenesis are likely linked with each other. Collateral formation is dependent not only on growth factors such as bFGF,24 but also on the mass of metabolically active skeletal muscle! ${ }^{3}$ Regenerating muscle produces abundant angiogenic growth factors and induces angiogenesis. Myocyte regeneration occurs only under oxygen supply that is supported by blood perfusion through collaterals? in agreement with our findings. HGF and bFGF potentially promote the growth of skeletal muscle?22,25 Taken together, the findings indicate that ischemia induces responses to injury in both the vasculature and skeletal muscle, and that HBO enhanced most of these responses. HBO-enhanced growth factor production likely promotes muscle regeneration. Conversely, regenerated muscle promotes neoangiogenesis and collateral formation by producing angiogenesis factors and angiogenic metabolites, leading to functional and morphological recovery of ischemia.

One unanswered question is the role of the intermittent nature of HBO. Mice were placed under HBO for only $1 \mathrm{~h} /$ day, and the tissue was exposed to ischemia for the remaining time. This protocol was similar to that used clinically, but makes it difficult to compare our findings with most of the previous in vitro data, which were obtained under continuous hypoxia!5,22 Because HBO administered to the sham-operated mice did not show any significant effects, the cyclic change of hypoxia and hyperoxia is important for the exaggerated expression of angiogenic growth factors. Oxygenation after ischemia enhances myocyte differentiation, and the effect is influenced by the duration of ischemia? Favorable effects of HBO on blood perfusion and muscle regeneration may be attributed to intermittent HBO during ischemia, and could change depending on the duration and frequency of the HBO treatment. Optimal conditions for recovery remain to be determined. Intermittent treatment has been reported to improve angiogenesis in ischemic hind limbs ${ }^{26}$

HBO is used to treat difficult wounds such as diabetic foot and arterial ulcers, but the benefit is rather limited! The present study shows that HBO exerts its effects by stimulating muscle regeneration from precursor cells. In chronic ischemia, skeletal muscle is atrophic and precursor 
cells are lost ${ }^{12}$ which may account for the modest effect of HBO therapy in chronic limb ischemia ${ }^{27,28}$ HBO may be a useful modality for promoting angiogenesis and myogenesis in combination with transplantation of precursor skeletal muscle and vascular cells.

\section{Acknowledgments}

This work was supported by Special Coordination Funds for Promoting Science and Technology from Ministry of Education, Culture, Sports, Science and Technology.

\section{References}

1. Kranke P, Bennett M, Roeckl-Wiedmann I, Debus S. Hyperbaric oxygen therapy for chronic wounds. Cochrane Database Sys Rev 2004; CD004123.

2. Rissanen TT, Vajanto I, Hiltunen MO, Rutanen J, Kettunen MI, Niemi $\mathrm{M}$, et al. Expression of vascular endothelial growth factor and vascular endothelial growth factor receptor-2 (KDR/Flk-1) in ischemic skeletal muscle and its regeneration. Am J Pathol 2002; 160: 1393-1403.

3. Marti HH, Risau W. Systemic hypoxia changes the organ-specific distribution of vascular endothelial growth factor and its receptor. Proc Natl Acad Sci USA 1998; 95: 15809-15814.

4. Onimaru M, Yonemitsu Y, Taiji M, Nakagawa K, Masaki I, Okano S, et al. Fibroblast growth factor-2 gene transfer can stimulate hepatocyte growth factor expression irrespective of hypoxia-mediated downregulation in ischemic limbs. Circ Res 2002; 91: 923-930.

5. Vincent KA, Feron O, Kelly RA, Harnessing the response to tissue hypoxia, HIF-1-a and therapeutic angiogenesis. Trends Cardiovasc Med 2002; 12: 362-367.

6. Lee YS, Jang HS, Kim JM, Lee JS, Lee JY, Li Kim K, et al. Adenoviral-mediated delivery of early growth response factor-1 gene increases tissue perfusion in a murine model of hind limb ischemia. Mol Ther 2005; 12: 328-336.

7. Santiago FS, Lowe H, Day FL, Chesterman CN, Khachigian LM. Early Growth response factor- 1 induction by injury is triggered by release and paracrine activation by fibroblast growth factor-2. Am J Pathol 1999; 154: 937-944.

8. Morishita R, Nakamura S, Hayashi S, Taniyama Y, Moriguchi A, Nagano T, et al. Therapeutic angiogenesis induced by human recombinant hepatocyte growth factor in rabbit hind limb ischemia model as cytokine supplement therapy. Hypertension 1999; 33: $1379-$ 1384.

9. Yun Z, Lin Q, Giaccia AJ. Adaptive myogenesis under hypoxia. Mol Cell Biol 2005; 25: 3040-3055.

10. Scholz D, Thomas S, Sass S, Podzuweit T. Angiogenesis and myogenesis as two facets of inflammatory post-ischemic tissue regeneration. Mol Cell Biochem 2003; 246: 57-67.

11. Di Carlo A, De Mori R, Martelli F, Pompilio G, Capogrossi MC, Germani A. Hypoxia inhibits myogenic differentiation through accelerated MyoD degeneration. J Biol Chem 2004; 279: 16332 16338.

12. Mitchell PO, Pavlath G. Skeletal muscle atrophy leads to loss and dysfunction of muscle precursor cells. Am J Physiol Cell Physiol
2004; 287: $1753-1762$.

13. Deindl E, Buschmann I, Hoefer IE, Podzuweit T, Boengler K, Vogel $\mathrm{S}$, et al. Role of ischemia and of hypoxia-inducible genes in arteriogenesis after femoral artery occlusion in the rabbit. Circ Res 2001; 89: $779-786$.

14. Takahashi A, Kureishi Y, Yang J, Luo Z, Guo K, Mukhopadhyay D, et al. Myogenic Akt signaling regulates blood vessel recuruitment during myofiber growth. Mol Cell Biol 2002; 22: 4803-4814.

15. Neuhaus P, Oustanina S, Loch T, Kruger M, Bober E, Dono R, et al. Reduced mobility of fibroblast growth factor (FGF)-deficient myoblasts might contribute to dystrophic changes in the musculature of FGF2/FGF6/mdx triple-mutant mice. Mol Cell Biol 2003; 23: 6037-6048.

16. Cao R, Ebba B, Robert P, David W, Mark JP, Eric W, et al. Angiogenic synergism, vascular stability and improvement of hind-limb ischemia by a combination of PDGF-BB and FGF-2. Nat Med 2003; 9: $604-613$.

17. Virag JI, Murry CE. Myofibroblast and endothelial cell proliferation during murine myocardial infarct repair. Am J Pathol 2003; 163: 2433-2440.

18. Masaki I, Yonemitsu Y, Yamashita A, Sata S, Tanji M, Komori K, et al. Angiogenic gene therapy for experimental critical limb ischemia: Acceleration of limb loss by overexpression of vascular endothelial growth factor 165 but not of fibroblast growth factor-2. Circ Res 2002; 90: 966-973.

19. Baumgartner I, Isner JM. Somatic gene therapy in the cardiovascular system. Ann Rev Physiol 2001; 63: 427-450.

20. Sullivan CJ, Doetschman T, Hoying JB. Targeted disruption of the Fgf2 gene dose not affect vascular growth in the mouse ischemic hind limb. J Appl Physiol 2002; 93: 2009-2017.

21. Farmy RG, Dass C, Sun LQ, Chesterman CN, Khachigian LM. Transcription factor Egr-1 supports FGF-dependent angiogenesis during neovascularization and tumor growth. Nat Med 2003; 9: 1026-1032.

22. Volonte D, Liu Y, Galbiati F. The modulation of caveolin-1 expression controls satellite cell activation during muscle repair. FASEB $J$ 2005; 19: 237-239.

23. Shao ZQ, Takaji K, Katayama Y, Kunimoto R, Sakaguchi H, Lai ZF, et al. Effects of intramyocardial administration of slow-release basic fibroblast growth factor on angiogenesis and ventricular remodeling in a rat infarct model. Circ J 2006; 70: 471-474.

24. Hirose K, Fujita M, Marui A, Arai Y, Sakaguchi H, Huang Y, et al. Combined treatment of sustained-release basic fibroblast growth factor and sarpogrelate enhances collateral blood flow effectively in rabbit hind limb ischemia. Circ J 2006; 70: 1190-1194.

25. Doukas J, Blease K, Craig D, Ma C, Chandler LA, Sosnowski BA, et al. Delivery of FGF genes to would repair cells enhances arteriogenesis and myogenesis in skeletal muscle. Mol Ther 2002; 5: 517-527.

26. Akasaki Y, Miyata M, Eto H, Shirasawa T, Hamada N, Ikeda Y, et al. Repeated thermal therapy up-regulates endothelial nitric oxide synthethase and augments angiogenesis in a mouse model of hind limb ischemia. Circ J 2006; 70: 463-470.

27. Wang D, Mayo M, Baldwin AS Jr. Basic fibroblast growth factor transcriptional autoregulation requires EGR-1. Oncogene 1997; 14: 2291-2299.

28. Wang C, Schwaitzberg S, Berliner E, Zarin DA, Lau J. Hyperbaric oxygen for treating wounds: A systemic review of the literature. Arch Surg 2003; 138: 272-279. 